screen all these women for the serum lipid abnormalities. But if a woman is known to be hyperlipaemic or has a relevant family history, and a combined form of oral contraceptive is to be rsed, at least the serum should be examined for opalescence, and if possible, serum lipids should be measured before and periodically during therapy. But the occurrence of bouts of abdominal pain should bring to mind this association of hyperlipaemia and pancreatitis.

1 Davidoff, F., Tishler, S., and Rosoff, C., New England fournal of Medicine, 1973, 289, 552 .

- Fredrickson, D. S., Levy, R. I., and Lees, R. S., New England fournal of Medicine, 1967, 276, 148 .

3 Bank, S., and Marks, I. N., Postgraduate Medical Fournal, 1970, 46, 576. 4 Zorilla, E., Hernandez, A., Hulse, M., and Gershberg, H., Clinical Research, 1968, 16, 356.

5 Ford, S., Bozian, R. C., and Knowles, H. C., Clinical Research, 1967, 15,

${ }_{6}^{6}$ Poulsen, H. M., Acta Medica Scandinavica, 1950, 138, 413.

7 Havel, R. J., Advances in Internal Medicine, 1969, 15, 117.

" Glueck, C. J., Levy, R. I., and Fredrickson, D. S., Annals of Internal Medicine: 1971, 75, 345.

\section{Psychiatric Safeguards}

Registered medical practitioners do not hold a monopoly of the art of healing. Even within the bounds of medicine in its broadest sense this is true, for they are assisted by nurses and a veritable army of skilled ancillaries such as laboratory technicians, biochemists, physicists, and physiotherapists. Even so, doctors by virtue of their training are the only ones who can assume full clinical and indeed legal responsibility for their patients, a responsibility shouldered by consultants inside and general practitioners outside the hospital service. It cannot be a question of primus inter pares: doctors must be, and must be seen to be, the captains of teams concerned with the care of patients.

In the treatment of patients suffering from mental disorders the relation is the same between psychiatrists and clinical psychologists. Some years ago in the U.S.A. disquiet arose as a result of the eruption of psychotherapists, lay and medical, belonging to orthodox and some very unorthodox schools of psychotherapy to meet the growing demand for treatment. In 1951 J. C. Whitehorn, ${ }^{1}$ in his presidential address to the American Psychiatric Association, found it necessary to give the findings of its Committee on Clinical Psychology as follows: (1) The American Psychiatric Association is strongly opposed to independent private practice of psychotherapy by the clinical psychologist; and (2) the Association believes that psychotherapy, whenever practised, should be done in a setting where adequate psychiatric safeguards are provided. Though it would be unfair to compare in quantitative terms the demand for psychotherapy in Britain and the U.S.A., the Royal College of Psychiatrists has recently felt constrained to publish a memorandum ${ }^{2}$ on the role of psychologists in the Health Service. It pays particular attention to the possible setting-up of independent departments of psychology within the hospital service, thus allowing the hospital consultant psychiatrist to be by-passed by direct referrals from general practitioners or consultants in other specialties.

The memorandum gives a brief history of the development of clinical psychology. Initially, it points out, great emphasis was laid on "testing," which became the preserve of "ffully trained psychologists." More recently, it goes on, there bas been a growing realization of the limitations of these tests, and at the same time there has been a shift of emphasis away from testing towards treatment. As an example, the involvement of clinical psychologists in various forms of behaviour therapy is cited. These procedures, it is pointed out, are not without their dangers, so that as a side issue the question of legal responsibility arises.

The most important section of the memorandum is concerned with what is described as "The physical factor and the concept of "caring'." Here what is highlighted is the relationship between physical and psychological causes of symptoms or of behavioural abnormalities, phenomena only doctors are trained to understand. Conditions such as cerebral tumours, neurological disorders, spontaneous hypoglycaemia, thyroid dysfunction, and drug dependence are cited as examples. Furthermore, a time may come in the course of psychotherapy when the patient needs physical treatments such as E.C.T. or drugs. Clinical psychologists, it is emphasized, are in no position to recommend one or prescribe the other. Again, many of the potent drugs now used in the treatment of mental disorder carry a risk of adverse effects. Doctors are the only ones qualified to detect and treat these reactions.

It is apparent from this closely argued memorandum that psychiatrists in Britain have rather belatedly come into line with their American colleagues. And its most far-reaching conclusion is that "Direct referrals of patients suffering from mental illness or behavioural abnormalities to clinical psychologists should not take place, since a psychiatric evaluation is essential."

1 Whitehorn, J. C., American fournal of Psychiatry, 1951-2, 108, 1.

2 Royal College of Psychiatrists, News and Notes, Supplement to British fournal of Psychiatry. September 1973.

\section{Follow-up of Coronary Disease}

Before coronary arteriography was possible the pathological state of the arteries in coronary arterial disease could be assessed only at necropsy. Now coronary arteriography enables this correlation to be made during life.

Recently a five to nine-year follow-up of 590 cases of angina pectoris ( 527 men and 63 women) has appeared. These patients were examined by selective coronary arteriography ${ }^{1}$ and by left ventriculography. ${ }^{2}$ The indication for these procedures was nearly always chest pain. Patients with congenital or rheumatic heart disease and those who had undergone coronary surgery within five years of coronary arteriography were excluded. The study was undertaken between 1963 and 1965, a time when implantation of a single internal mammery artery was the most common surgical procedure. All patients had $50 \%$ or more obstruction of at least one major coronary artery. Death attributable to coronary disease occurred in 244 out of the 263 who died during the five years following arteriography. This period was used as a basis of comparison in evaluating prognosis.

The 37 patients with disease of the left main coronary artery had a five-year mortality rate of $57 \%$, and it was highest in the first year after arteriography. Additional narrowing of the remaining coronary arteries carried an even worse prognosis. The 202 further cases with disease in a single vessel had a 5-year mortality rate of $15 \%$. Moderately severe obstruction (over $50 \%$ ) of the left anterior descending artery had the poorest prognosis, moderately severe obstruction of the right the best. Narrowing of the circumflex artery occupied an intermediate position. Additional moderate narrowing (more than $30 \%$ but 